\title{
The Practices of Existential Psychotherapists: Development and Application of an Observational Grid
}

Edgar A. Correia, Vítor Sartóris, Tiago Fernandes, Mick Cooper, Lucia Berdondini, Daniel Sousa, Branca Sá Pires, João da Fonseca

Authors' Notes

Edgar A. Correia, School of Psychological Sciences and Health, University of Strathclyde, Glasgow G1 1QE, UK; Address: Rua de Cabo Verde, nº $102^{\circ}$ Dto., 1170067, Lisboa, Portugal; Mobile: +351 964113002; E-mail: edgar.agrela@gmail.com

Vítor Sartóris, ISPA - University Institute, Lisbon, Portugal; Address: Rua Afonso Lopes Vieira, n³0 Charneca da Caparica, Portugal; Mobile: +351 916356 283; E-mail: vsartoris@gmail.com

Tiago Miguel dos Santos Fernandes, ISPA - University Institute, Lisbon, Portugal; Address: Rua Principal n45, 2565-292 - Freiria, Portugal; Mobile: +351 917717752; Email: fernas1989@hotmail.com

Mick Cooper, Department of Psychology, University of Roehampton, London, SW15 4JD, UK; Tel: +44 (0) 208392 3741; Mobile: 07734-558155; E-mail $\underline{\text { mick.cooper@roehampton.ac.uk }}$ 
Lucia Berdondini, School of Psychological Sciences and Health, University of Strathclyde, 40 George Street, room GH518,Glasgow G1 1QE, UK; E-mail: lucia.berdondini@strath.ac.uk

Daniel Sousa, ISPA - University Institute, Lisbon, Portugal; Address: Rua Jardim do Tabaco, 44, Rua Jardim do Tabaco, 34, 1149-041 Lisboa; Mobile: +351 917854852; Email: daniel@ispa.pt

Branca Sá Pires, Sociedade Portuguesa de Psicoterapia Existencial (SPPE), Lisbon, Portugal; Address: Rua Ramalho Ortigão, Vila Marisa, 35D, 2-Dto. 2775-268 Parede; E-mail: brancasapires@ @otmail.com

João Eusébio da Fonseca, Sociedade Portuguesa de Psicoterapia Existencial (SPPE), Lisbon, Portugal; Address: Rua João Luís Ricardo, n²5, 2º B, 2775-211 Parede, Portugal. Mobile: +351 917867840; E-mail: joaodafonsecapsi@gmail.com

Correspondence concerning this article should be addressed to Edgar A. Correia, Rua de Cabo Verde, $\mathrm{n}^{\circ} 102^{\circ}$ Dto., 1170-067, Lisboa, Portugal. Mobile: +351 964113002; Email: edgar.agrela@gmail.com 
This work was supported by the Fundação para a Ciência e a Tecnologia (FCT),

Ministério da Educação e Ciência, Portugal, under Grant SFRH/BD/71484/2010.

\title{
Ethical standards
}

This investigation was granted ethical approval by the Instituto Superior de Psicologia Aplicada Ethics Committee. All clients were fully informed of research procedures and all of them gave their informed consent.

Word count (exc. tables): 8,307 words

The Practices of Existential Psychotherapists: Development and Application of an

\section{Observational Grid}

\begin{abstract}
Within the major therapeutic paradigms, observational instruments have been developed to assess orientation-specific interventions or processes. However, to date, no such instrument exists to assess existential practices. Recent research indicates the key practices of existential therapists, and forms an empirical basis on which to develop an observatory grid. This paper describes the development of such a grid, and its exploratory testing with eight clients of four Portuguese existential psychotherapists. A total of 32 sessions were observed and both speaking turn and whole session analysis showed that it was feasible to assess existential therapy using the instrument, although psychometric findings recommend further refinement of the tool. Session rating data suggests that the chief practices applied by existential therapists were relational,
\end{abstract}


followed by the use of hermeneutic interventions and reformulations. Interventions based on phenomenological and existential assumptions were observable in practice but limited in frequency. Further refinements and developments of the observational grid, together with additional research - using a range of therapists from different schools of existential therapy - are recommended.

\section{Keywords}

Existential therapy; existential-specific practices; observational study; exploratory study; treatment adherence. 


\section{The Practices of Existential Psychotherapists: Development and Application of an Observational Grid}

It has been claimed that existential psychotherapy is growing (Barnett \& Madison, 2012; du Plock \& Deurzen, 2015). Recent research confirms that it is practiced in at least 48 countries, and that 239 institutions globally provide some sort of training in existential or existentially-informed counselling or psychotherapy (Correia, Cooper, \& Berdondini, 2014). It is one of the longest-established forms of psychotherapy (Cooper, 2012), but until recently existential practices have not been systematically documented in an agreed way (Correia, Cooper, Berdondini, \& Correia, 2016). This has prevented the rigorous evaluation of the effectiveness of existential interventions and processes (Correia, Cooper, \& Berdondini, 2015; Keshen, 2006; Norcross, 1987; Rayner \& Vitali, 2014). Consequently, the development of clear, straightforward and evidence-based recommendations for the global community of therapeutic practitioners have been almost non-existent (Cooper, 2012; Vos, Cooper, Correia, \& Craig, 2015a, 2015b).

Existential authors argue for the singularity and specificity of each therapist, client, and dyad (Correia, 2005): Every therapeutic process is perceived as unique, with its own therapeutic demands (Lantz, 2004), not possible to replicate, nor compatible with universal procedures or interventions (Correia, 2005; Deurzen \& Adams, 2011). Only recently have a few authors been explicitly addressing their understanding of the therapeutic procedures that characterize the existential practice (e.g., Cooper, 2015; Deurzen, 2012; Deurzen \& Adams, 2011; Längle, 2013; Schneider, 2008; Sousa, 2015; 
Spinelli, 2007; Yalom, 2001) and only three studies (Alegria et al., 2016; Correia et al., 2016; Norcross, 1987) have empirically investigated it.

In the 1980s, Norcross (1987) asked 33 American existential psychologists and psychotherapists to indicate the frequency with which they employed a range of therapeutic interventions from a 99-item questionnaire. The most frequently selfreported practices were Rogerian skills (e.g., expressing warmth, trying to understand the patient's reality), authenticity (being genuine with the client), evaluation of clients' nonverbal behaviour and therapist self-disclosure, while flooding and psychometric evaluation were existential therapists' least used practices.

Correia and colleagues (Correia, Cooper, Berdondini, \& Correia, 2015; Correia et al., 2016; Correia, Correia, Cooper, \& Berdondini, 2014a, 2014b) developed an international survey asking existential counsellors and therapists from different theoretical backgrounds, which specific methods or practices they consider most characteristic of existential therapy. A total of 971 existential practitioners, from 46 countries, responded. Content analysis was conducted on their open-ended answers and five overarching categories emerged.

Phenomenological practices was the most frequent category in the Correia et al. (2016) study and covered sub-categories such as the use of the phenomenological method of enquiry, adopting a phenomenological attitude towards the contents brought to the session by clients, and interpretations from a hermeneutic stance. The next most frequent were methods of specific existential branches, which covered very specific practices associated with classic logotherapy (e.g., paradoxical intention, dereflexion), Längle's existential analysis (e.g., the method of Personal Existential Analysis) and Sartrean-based therapy (e.g., the progressive-regressive method). Practices informed by existential assumptions was the third most frequent category and referred to helping 
clients to explore and/or acknowledge the impact and relation they had with a range of existential philosophical assumptions, in particular the "existential givens" (e.g., freedom, interrelatedness, uncertainty, finitude). This was followed by the relational practices category, which covered sub-categories of attitudes or stances that promoted a good therapeutic relation (e.g., presence, encounter, the Rogerian relational attitudes), addressing what happens in the therapeutic relation, and relational skill (e.g., therapeutic listening and dialogue). Less common were practices of other therapeutic paradigms, of which experiential and body practices was the most prevalent sub-category (Correia et al., 2016).

Correia et al.'s (2016) account of existential practitioners' perspective of their main therapeutic procedures was an important step to clarify, specify and systematize existential practices. However, this data concerns practitioners' self-reported beliefs about what they do, and not necessarily evidence of what they do in practice. An interesting and important research question, therefore concerns existential practitioners' actual adherence to practices that they report as most characteristic of existential therapy.

Alegria et al.'s (2016) is the single study that has tried to map out the actual therapeutic processes taking place during existential therapy sessions. Using the “Psychotherapy Process Q-Set” (PQS), one-year's existential therapy sessions of four Portuguese client-therapist dyads were analysed. It was found that six of the 10 most characteristic elements of the therapeutic process were related to attitudes and actions of the therapist. These were: a) Therapist emphasizes patient feelings in order to help him or her experience them more deeply; b) Therapist is sensitive to the patient's feelings, attuned to the patient; empathic; c) Therapist clarifies, restates, or rephrases patient's communication; d) Therapist communicates with patient in a clear, coherent style; e) 
Therapist accurately perceives the therapeutic process; f) Therapist is confident or selfassured (vs. uncertain or defensive).

While Norcross (1987), Correia et al. (2016) and Alegria et al. (2016) all identify the therapeutic relationship as a salient element of existential practice, only Correia et al.'s (2016) survey identifies phenomenology, existential assumptions, and methods of specific existential branches. It may be that these existential-specific selfreported practices are not actually applied by existential practitioners in real practice, or it may be that the instrument used by Alegria et al. (and the instrument used by Norcross) was not able to capture existential therapy's specific practices: Although considered a valid instrument for different therapies, the PQS was initially designed for psychoanalytic, cognitive-behavioural, and interpersonal therapies (Smith-Hansen, Levy, Seybert, Erhardt, \& Ablon, 2012) and lacks specific items considering phenomenology, existential assumptions or methods of specific existential branches.

To evaluate the effectiveness of existential-specific interventions or processes, it is first necessary to verify if existential practitioners do actually apply or implement them. This kind of question relates to what has been denominated treatment adherence: "the extent to which interventions considered integral to the treatment model(s) are delivered” (McLeod, Smith, Southam-Gerow, Weisz, \& Kendall, 2015, p. 315). Treatment adherence has been the most evaluated factor for treatment integrity (or implementation integrity), as an instrument for the experimental validity of studies concerning the efficacy of specific practices or methods (Perepletchikova, Treat, \& Kazdin, 2007).

There are instruments developed to measure treatment adherence to specific therapeutic interventions related to cognitive, behavioral, psychodynamic, clientcentered, interpersonal and family therapies (McLeod et al., 2015; Perepletchikova et 
al., 2007), but no instrument was found to verify whether a session or course of treatment is delivered consistently in adherence with existential therapy's most characteristic practices.

To rigorously develop research on the efficacy of existential specific practices, there is a need to adequately address treatment integrity, in particular treatment adherence (Perepletchikova, et al., 2007). To study psychotherapeutic processes specific to the existential practice, there is a need to develop instruments able to capture them. Direct observation methods are considered the most effective way to measure therapists' commitment to the particular interventions being evaluated (Perepletchikova, et al., 2007). Until recently there was no consensual and systematized list of existential practices from which to develop observational instruments to measure these factors. Correia and colleagues' (2016) gives a largely consensual and empirically based pool of existential practices, which may stand as a valid base to develop an observational instrument with existential-specific items. Such an instrument may help to clarify what existential therapists actually do in real existential practice and measure treatment adherence to existential specific interventions.

The present paper's primary aim is to pilot the development of an observational grid for existential therapy, based on the self-reported most characteristic existential practices, as collected in Correia et al. (2016). Accordingly, the primary research question is (Steps 1, 2 and 3 of this Study): Can the self-reported existential practices be operationalized into a reliable observational instrument to code existential therapy sessions? A secondary aim is to verify if the self-reported core existential practices are actually applied (treatment adherence) during a real client-therapist interaction. Secondary research questions are the following (Step 4 of this Study): a) What practices are most frequently used by existential therapists in real interventions? b) Do existential 
practitioners adhere to the existential-specific practices during real client-therapist interactions? c) Are there differences among therapists in their use of the different practices? d) Do differences among clients influence the practices used by their therapist?

\section{Methods}

\section{Summary of Design}

Based on an informal consensus development method, an exploratory observational grid was designed for existential therapy, building on data from Correia et al. (2016). Using a non-participant observation method the observational grid was applied and inter-rater reliability was assessed for reliability testing and descriptive and inferential statistical analysis was performed over the coded interventions to verify treatment adherence.

\section{Participants}

\section{Clients.}

Client-participants were outpatients of a Portuguese university clinic. All the thirteen new clients that sought this clinic for psychotherapy between May and December 2011 were informed of the research program and invited to participate. The 10 interested clients were fully informed of research procedures and accepted by giving 
their informed consent. Sessions from two clients had sound-recorded problems and where excluded from present research.

Eight Caucasian clients, one man and seven women, aged between 25 and 65, participated in this study. CORE-OM scores of psychological well-being, between 15.3 and 19.7, indicated a moderate level of severity at first session, above the clinical cutoff point (Barkham, Mellor-Clark, Connell, \& Cahill, 2006).

\section{Therapists.}

Therapists' inclusion criteria were: a) Certified professional training as existential psychotherapists and; b) More than five years of clinical experience. Four chartered Portuguese psychotherapists (one woman and three men) worked with two clients each over 24 psychotherapy sessions. Aged between 30 and 42, they all have had professional training as existential psychotherapists and have professional experience ranging between six and 13 years. They are all recognized existential psychotherapists and trainers at the Portuguese Society for Existential Psychotherapy (SPPE).

SPPE recognizes itself as part of the existential-phenomenological branch of existential therapy (Correia, Cooper, et al., 2014) and its members are deeply influenced by the British School of Existential Therapy (Cooper, 2012; Correia, Correia, et al., 2014a). Theoretically, Portuguese existential therapists assume a more hermeneuticanalytical practice, described as a "genetic phenomenological" approach (Sousa, 2015). In the Correia, Correia, et al. (2014a) survey, they considered phenomenological practices as the most characteristic of the existential therapy, followed by relational practices and practices informed by existential assumptions. 


\section{Analysts and panel for the development of the observational grid.}

Analysis was performed by two Portuguese, Caucasian male clinical psychology MA students ( $2^{\text {nd }}$ and $3^{\text {rd }}$ author), with no previous specific training or practice in existential therapy.

The panel for the consensual development of the observational grid (panel) was composed of six elements: the two analysts (or raters) and four experts. The experts (one female and three male) were psychologists and psychotherapists, with extensive experience in psychotherapy, psychotherapy research and qualitative research studies. Two experts were trained and certified existential therapists, while the other two experts were trained in other therapeutic paradigms (experiential and gestalt therapy).

\section{Procedures}

The therapy sessions took place between June 2011 and September 2012 at a university clinic facility in Lisbon. Client-therapist dyads were chosen by clients, according to the available time schedule of each therapist.

All sessions were recorded with a digital sound recorder. To avoid the particularities inherent to initial and final sessions (Rubel, Lutz, \& Schulte, 2015), only middle sessions were used. During the instrument development process, raters' training was carried out, and inter-rater reliability was assessed, based on sessions seven to 10 , and 15 to 18 . The final version of the observational grid was applied over sessions 11 to 14 , amounting to 32 analyzed sessions (four sessions per client).

Both speaking turn and session were the chosen units of analysis (Elliott, 1993). Speaking turn analysis (a single uninterrupted utterance by the therapist, except for 
backchannels utterances that do not interrupt the client - e.g., "Mhm", "Yeah") was chosen because it corresponds, most of the time, to a therapist intervention, i.e., to the application of a particular practice: Aiming to verify the applied practices, this unit of analysis seems the most natural and valuable (Elliott, 1993). Session analysis (whole session as a unit) was also chosen because it is built out of several episodes, having the advantage of capturing practices that require larger units than a speaking turn (Elliott, 1993).

Separately, analysts heard and rated each therapist speaking turn and whole session, according to the items of an observational grid, developed systematically on a process of refinement-training-application-assessment.

The instrument was developed based on an informal consensus among members of the panel. Members of the panel were aware of each other and of the aims of the study. The first author was responsible for informing, questioning, exchanging and gathering consensus among them. Questions were not predetermined or structured in advance and were posed according to the problems generated by the systematic iteration process of refinement-training-application-assessment.

The iteration process for the grid development (Step 1) was continued until an instrument was established that permitted substantial agreement (Landis \& Koch, 1977) between analysts, as assessed by the inter-rater reliability for the coding of two sessions. Once this goal was achieved, the panel was dissolved and the final version of the observational grid was applied independently by the analysts over the 32 sessions (Step 2). Reliability testing was performed comparing raters' independent analysis (Step 3). Inconsistencies in scoring were resolved by consensus between analysts and nonconsensual ratings were arbitrated by the first author. Descriptive and inferential statistics were conducted to analyze the secondary research questions (Step 4). 


\section{Step 1 - Instrument development process.}

\section{First observational grid.}

\section{Development.}

As Correia and colleagues' (2016) research gives a largely consensual and empirically based pool of existential practices, the panel agreed that the grid for observational analysis should build directly upon the codes identified in the content analysis (see Correia et al., 2016) as these most closely match the specific interventions reported by the existential practitioners.

The choice for the whole-session observer-based methodology was based on the approach most widely used to evaluate treatment adherence: Extensiveness ratings, comprising both frequency and thoroughness (McLeod et al., 2015), were conducted using a 5-point Likert-type scale to measure the degree to which each therapist engages in each intervention during the entire session. As the therapist's single utterances could comprise more than one practice, the panel's choice for the speaking turn observerbased methodology was to code each therapist utterance for up to three different practices they believed were being used.

\section{Training.}

The two analysts were trained by the first author to recognize the 77 coded practices used in a real therapy session. First, they were provided with a manual containing the practices' definition, to familiarize themselves with the descriptions of the practices. Next, training consisted of four hours of theoretical teaching, followed by 21 hours analyzing nine audio-recorded sessions of different client-therapist dyads, with 
the first author supervising. Analysts had a further four hours training together, analyzing two other transcribed sessions.

\section{Application.}

Separately, analysts applied the observational grid over two sessions from two different client-therapist dyads. Analysts rated each therapist speaking turn for up to three different practices they believed were being used. After hearing the whole session, they had to rate the presence of each of the 77 practices with a five-item Likerttype scale: 0 (not present) to 4 (very frequent).

\section{Assessment.}

Several practices were found to have low frequency counts (only 12 of the 77 practices were found) and the analysts found it impractical managing 77 items simultaneously. In addition, many items had very similar and overlapping definitions (e.g., Presence, Encounter and Therapeutic relation), making them difficult to distinguish when rating real practice interventions. Furthermore, having up to three different practices to choose from for each speaking turn made inter-rater agreement difficult to calculate. In fact, Cohen's Kappa was used to test reliability between the two observers regarding speaking turn analysis and only moderate agreement (Landis \& Koch, 1977) was achieved: $\kappa=.430 ; p<.001$.

\section{Second observational grid.}

\section{Refinement.}

Based on the difficulties reported by the analysts using the first observational grid, the experts suggested eliminating or combining the 77 codes of practice into a 
smaller number of umbrella categories, to reduce analysts' rating load and the redundancies among items. Correia and colleagues' (2016) 17 clustering sub-categories of the 77 coded practices were proposed and accepted unanimously by the panel as the items for the second observational grid: the direct derivation from a consensual and empirically based source sustained this consensus.

As having up to three different practices to choose from for each speaking turn made inter-rater agreement difficult to calculate, the experts suggested changing the observer-based methodology to rate each of the 17 sub-categories as present or absent (dummy or binary variable) in each therapist turn.

\section{Training.}

The two analysts were provided with a manual containing the practices' definitions, to familiarize themselves with the descriptions of the practices. With supervision by the first author, the analysts had one hour of theoretical training, followed by ten hours using the new observational grid, with four different dyads' sessions.

\section{Application.}

Separately, the two analysts applied the 17-item grid to two audio-recorded sessions. As the main problems of the first observational grid were related to the grid items and not with the unit of analysis, and in order to reduce raters' workload, whole session analysis was not performed at this point.

Assessment. 
The training experience and effective application led the first author and analysts to conclude that the 17-item grid was easier to apply, but the binary coding method added greater subjectivity: It was difficult to rate, at every single speaking turn, the presence/absence of attitudinal interventions (e.g., relational stances as Presence or establishing a good therapeutic relation). On the other hand, practices such as Deepening awareness and Relational skills (e.g., Therapeutic listening and Dialogue), were rated as present on almost every therapist intervention, rendering these as redundant categories.

Coded as dummy variables, inter-rater reliability was calculated for every grid item. Two substantial agreements (Landis \& Koch, 1977) were achieved $(\kappa=.656, p<$ $.001, \kappa=.634, p<.001)$, for Interactive interventions and Phenomenology based attitudes and practices, respectively. For the remaining 15 items raters had moderate, fair or slight agreement (Landis \& Koch, 1977). Six items were not possible to compute due to low frequency counts.

\section{Third observational grid.}

\section{Refinement.}

To overcome the redundancy and low frequency count problems found on the second observational grid, the experts suggested merging some grid items. To remain faithful to Correia et al.'s (2016) findings, the panel agreed to cluster the 17 items from the second iteration of the observational grid according to the five overarching categories of practice found in that study. From their experience in analyzing audio recorded sessions up to that point, both the analysts and the first author reported that the sub-categories Addressing what is happening in the therapeutic relation, Hermeneutic interventions, Experiential and body practices and Directive/confrontational 
interventions, appeared as very different and specific practices and, for that reason, they suggested that they stand as individual items. The whole panel agreed to maintain these four sub-categories as specific and independent items, concomitant with the five overarching categories of practice found in Correia et al. (2016).

As the binary coding method added greater subjectivity to the second iteration, it was decided that only the main practice of each speaking turn would be rated: the panel agreed that this change would reduce rater load and maintain statistical power. As some practices are not always directly observable as a main practice in the speaking turn unit of analysis, the panel decided that a session analysis was necessary and should be performed using a Likert type scale, over the nine practices.

\section{Training.}

The two analysts were provided with a manual containing the practices' definitions to familiarize themselves with. With supervision by the first author, the two analysts were trained using the new nine-item grid and procedures over five different audio recorded sessions, for a total ten hours' time.

\section{Application.}

Separately, the two analysts applied the third observational grid over two sessions from two different client-therapist dyads.

\section{Assessment.}

Inter-rater reliability was measured and a substantial agreement (Landis \& Koch, 1977) was achieved at both speaking turn analysis $-\kappa=.729 ; p<.001-$ and whole session analysis $-\kappa=.654 ; p<.001$. 
Based on this analysis, the panel unanimously agreed to use this nine-item "Existential Psychotherapy Observational Grid" (EPOG) as the instrument for a full study.

\section{Step 2 -Application of the observational grid.}

Instrument.

The EPOG consists of a list of nine duly explained (see definitions below) observable practices: Phenomenological practices; Methods associated with specific existential branches; Practices informed by existential assumptions; Relational practices; Addressing what is happening in the therapeutic relation; Hermeneutic interventions; Experiential and body practices; Directive/confrontational interventions and Other practices.

Phenomenological practices can be observed when the therapist makes use of the phenomenological method (focus on the phenomena as it shows itself) to enquire, question, describe or explore a particular subject with the client. The therapist stays open to the client's actual and unique experience of the problem, while bracketing his own assumptions, theories and prescriptions for that kind of problem.

Methods associated with specific existential branches, is rated whenever the therapist makes use of specific methods associated with logotherapy and/or existential analysis or with Sartrean-based therapy. These very specific methods include dereflexion, paradoxical intention, Socratic dialogue and all Längle's existential analysis step-wise methods (Längle, 2003, 2013). Sartrean-based methods include addressing dialectics and the progressive-regressive method.

The practices informed by existential assumptions can be observed when the therapist helps the client to address, explore and/or acknowledge the impact and relation 
the client has with particular existential-philosophical assumptions/presuppositions, including: The "givens" or unescapable conditions of existence (e.g., freedom, facticity, uncertainty, interrelatedness, temporality, paradoxes, being-in-the-world); the four worlds/dimensions of existence; personal worldviews to interpret the world; authenticity; the ontological structure of Dasein.

Relational practices include all relational attitudes and interventions adopted by the therapist. We see this happening when the therapist accepts and supports the client regardless of what they say or do; when the therapist is clearly and actively focused and engaged with the client and with what the client brings; when the therapist is clearly touched and connected with the client's experience; or when the therapist encourages a relation where both are equally human, so they can argue and look at each other's perspective from the same hierarchic position.

Addressing what is happening in the therapeutic relation is coded when the therapist works with the contents that may arise from/in the therapeutic relation, by analyzing it, working in the here-and-now, being aware of their reactions to the client, and/or by self-disclosing.

Hermeneutic interventions are observed when the therapist makes an interpretation (gives his or her understanding or analysis of a presented subject, or a link between different topics discussed previously) based on the content gathered from a previous phenomenological exploration or from contents brought by the client. These interpretations are always based on actual client material and never on the therapist's previous assumptions or theories.

Experiential and body practices can be observed when the therapist works on an experiential and/or body level, using practices such as focusing, body awareness, 
address and explore body sensations and/or expressions, creativity/expression methods (drawing, sculpture, dance, music, etc.) or Gestalt's empty-chair method.

Directive/confrontational interventions are rated when the therapist challenges the client's perspective, by interpreting (not based exclusively on contents brought by the client, but on the therapist's previous assumptions or theories), confronting, or pointing out certain aspects of what was said or done that seem contradictory, confused or even untrue. Or when the therapist tries to clarify what seems contradictory, unclear, or incomplete. The therapist may also use more directive interventions: Addressing client changes and outcomes, using clinical psychology evaluation methods or tests, or giving opinions, for example.

Other practices comprise all other interventions the therapist may use or adopts that do not fit in with the ones referred to above (e.g., mindfulness, narrative methods, working with dreams).

\section{Observer-based methodology.}

Analysts listened to the client-therapist interactions independently and rated each therapist speaking turn by choosing the main practice they believed was being used from the nine-item EPOG list. The chosen practice was directly recorded by the analysts on an SPSS database, according to the client-code and time that the therapist's utterance had initiated. Whenever the analyst could not decide between two practices, a second practice could be added, only to be considered if this second choice was coincident with the other rater's choice.

The whole-session observer-based methodology was based on extensiveness ratings (McLeod et al., 2015), built on the frequency counts from speaking turn analysis and on practices (e.g., attitudinal or process-based) which could only be observed in 
larger units of analysis, as conversational sequences or events (Elliott, 1993). All EPOG's nine items were rated according to a five-item Likert-type scale: "Not applied" (if a practice was not used at all, during the whole session); "Rarely applied" (if present one or two times); "Occasionally applied" (if present three to six times); "Frequently applied" (if present six to 12 times); and "Very Frequently" (if present more than 13 times). Session ratings were also directly computed by the analysts on an SPSS database.

To facilitate familiarity and understanding of stories and processes and to facilitate the distinction between hermeneutic interventions, interpretations and reformulations, analysts followed each client-therapist dyad along its four analyzed sessions, before changing to another dyad.

\section{EPOG's application.}

Analysts rated a total of 1,559 therapist speaking turns, from the 32 sessions of the eight different dyads, using the EPOG and the observer-based methodology described above (see Table 1 for a sample of a codified segment).

(Insert Table 1 around here)

Analysts reported the experience of finding Relational practices and Phenomenological practices as two overlapping items on many occasions, making them difficult to distinguish when rating real practice interventions: a) A therapist's spontaneous utterance that facilitates an open phenomenological exploration in the context of an intense relational moment could also be rated as an empathic relational response; b) A therapist's genuine curiosity or interest in wanting to know more about a 
client's subject that facilitates an open phenomenological exploration could also be rated as the Relational practices "listening" and "dialogue" (e.g., TC1 2'55" and 4'04', Table 1).

Practices informed by existential assumptions were reported as difficult to observe in single utterances but analysts also found it difficult to operationalize and objectively spot when therapists were using existential assumptions even in larger units of analysis too.

The remaining items were considered manageable and practicable. Attention was drown by the analysts to the fact that other practices were mainly reformulations.

\section{Step 3 - Instrument's reliability testing.}

Separated ratings were put together on a single SPSS database and Cohen's Kappa was run to determine if there was agreement between analysts. A moderate agreement (Landis \& Koch, 1977) was found at both speaking turn $(\kappa=.603 ; p<.001)$ and session analysis $(\kappa=.585 ; p<.001)$. When the second possible choice of observers was considered, a substantial agreement $(\kappa=.664 ; p<.001)$ was found between analysts at speaking turn analysis.

Major doubts and disagreements between analysts at speaking turn analysis occurred when rating practices informed by existential assumptions $(14.3 \%$ of agreements between raters), phenomenological practices (37\% of agreements) and directive/confrontational interventions (45.5\% of agreements). Major agreements were found on rating experiential and body practices (100\% agreement between raters), hermeneutic interventions ( $86.5 \%$ of agreements) and relational practices $(76.9 \%$ of agreements). 


\section{Step 4-Analysis.}

Analysts met together to find consensus over non-coincident ratings. A total consensus was achieved among observers for whole session analysis and for $97.8 \%(n=$ $1,525)$ of the speaking turn observations: the remaining therapists' interventions $(n=$ 34) were arbitrated by the first author.

Statistical descriptive analyses were conducted over speaking turn and whole session results. Chi-square tests were conducted to verify if observed practices at the speaking turn analysis were equally distributed by the different therapists and the different clients of the same therapist. In order to perform these inferential procedures, it was necessary to combine the three less rated items into one larger item (see Table 4 and 5).

\section{Results}

\section{Speaking Turn Analysis}

From the 1,559 therapist's speaking turns analyzed, the most frequently rated practices were the relational $(n=750,48.1 \%)$, followed by hermeneutic interventions $(n$ $=446,28.6 \%)$ and other practices $(n=201,12.9 \%)$ (see Table 2$)$. Then came the phenomenological practices $(n=84,5.4 \%)$, the directive/confrontational interventions ( $n=47,3 \%)$, addressing what is happening in the therapeutic relation $(n=22,1.4 \%)$, practices informed by existential assumptions $(n=6,0.4 \%)$ and experiential and body 
practices $(n=3,0.2 \%)$. Not a single application of methods associated with specific existential schools was observed in this sample.

(Insert Table 2 around here)

The most frequent specific interventions observed by analysts rating the other practices item were reformulations ( $n=162,80.6 \%$ of all rated other practices): e.g. "In other words, you were angry because she did not accept everything you brought." TC1$\left.8^{\prime} 08^{\prime \prime}\right)$. Nine out of the 201 other practices (4.5\%), were interventions echoing back what the client said.

\section{Whole Session Analysis}

At the session level of analysis, both relational and hermeneutic practices were rated as Very Frequent (modal rating) in $26(81.3 \%)$ and 15 (46.9\%) of the 32 analyzed sessions, respectively, and this was the modal response (see Table 3).

(Insert Table 3 around here)

Occasionally was the modal rating for other practices $(n=11,34.4 \%)$, with a similar distribution of sessions for the rest of the Likert scale. Phenomenological practices' modal rating was Rarely $(n=14,43.8 \%)$. Not present was the modal rating for directive/confrontational interventions $(n=12,37.5 \%)$, addressing what is happening in the therapeutic relation $(n=25,78.1 \%)$, practices informed by existential 
assumptions $(n=27 ; 84.4 \%)$ and experiential and body practices $(n=29,90.6 \%)$. Methods associated with specific existential schools were never present.

\section{Practices by Therapist and Clients at Speaking Turn Analysis}

There were significant differences among therapists in their use of the different practices: $X^{2}(15 ; n=1,559)=115.323 ; p<.001$ (see Table 4). Therapist $\mathrm{C}$ used fewer relational practices and more other practices than the other therapists. Therapist A used more phenomenological practices and Therapist B fewer other practices and more directive/confrontational interventions, when compared to the other therapists.

(Insert Table 4 around here)

To determine if differences between clients influenced the practices used by their therapist, chi-square tests were conducted on clients of the same therapist. Practices of therapists $\mathrm{C}\left(X^{2}(5 ; n=392)=12.077 ; p=.034\right)$ and $\mathrm{D}\left(X^{2}(5 ; n=637)\right.$ $=12.937 ; p=.024)$ were dependent on their clients, but no significant differences were found on practices of both therapists A and B (see Table 5). Therapist C used more hermeneutic interventions and addressed much more frequently what was happening in the therapeutic relation with Client 1, but used fewer other practices than with Client 2. Therapist D was more phenomenological with Client 2 and more hermeneutic with Client 1.

(Insert Table 5 around here) 


\section{Discussion}

\section{Existential-Specific Observational Instrument}

The developed instrument allowed analysts to produce acceptable inter-rater reliability (Landis \& Koch, 1977) at the first experimental application over two sessions. Notwithstanding, EPOG's reliability scores for the independent analysis of the 32 sessions showed lower values; below those reported for other observational measures (e.g., Carter et al., 2012; Froján-Parga, Calero-Elvira, \& Montaño-Fidalgo, 2011; Gonçalves, Ribeiro, Mendes, Matos, \& Santos, 2011; McLeod et al., 2015). Major inconsistencies between analysts were found particularly with the existential-specific categories (existential assumptions and phenomenological practices). This shows the need to further clarify the operational definition and the observable elements of these existential-specific practices and, as with other observational instruments, try to develop mutually exclusive categories (Gonçalves et al., 2011; Michie et al., 2013): “A well-specified intervention is essential before evaluation of effectiveness is worth undertaking" (Michie et al., 2013, p. 82), in order to address fidelity and consistency issues (Michie et al., 2013; Perepletchikova et al., 2007).

\section{Existential Interventions Observed in Real Practice}


Independent of client or therapist, relational practices were the most prevalent therapeutic procedures observed in all the 32 analyzed sessions of existential therapy. Hermeneutic interventions were the second most frequent practice, independent of therapist and clients, except for dyad TC2. Reformulations represented $10.4 \%$ of all therapists' interventions - almost double that of the rated phenomenological interventions.

The relevance of the relational practices and the frequent use of reformulations relate with Norcross' (1987) and Alegria and colleagues' (2016) findings. In the Correia et al. (2016) study, relational practices was an important category referred to by worldwide existential practitioners, and the second most frequent category for the Portuguese sample (Correia, Correia, et al., 2014a). Findings also corroborate literature that argues that the existential practice is centered on the therapeutic relation (e.g., Cooper, 2004; Martínez, 2012; Spinelli, 2007; Spinelli, 2008; Teixeira, 1996; van Kaam, 1966). Reformulations are not usually referred to in existential therapy literature and it was not considered by worldwide existential practitioners as a characteristic practice of their paradigm (Correia et al., 2016).

The frequent use of hermeneutic interventions was unexpected considering both the Norcross (1987) and the Alegria et al. (2016) results. The Correia et al. (2016) study refers to hermeneutic practices, but it did not represent more than $1.4 \%$ of worldwide practitioners' choices (see Error! Reference source not found.) and only $2.8 \%$ of that of the Portuguese (Correia, Correia, et al., 2014a): only daseinsanalysts attributed a major relevance (17.6\%) to hermeneutic based practices (Correia, Cooper, Berdondini, \& Correia, in press). Existential therapists may be using more interpretations (even if based on clients' previously brought material) than they admit 
or this may be a particular characteristic of Portuguese existential therapists, as they theoretically assume a more hermeneutic-analytical practice (Sousa, 2015).

Directive/confrontational interventions, addressing what is happening in the therapeutic relation, and experiential and body practices were referred to by existential practitioners as characteristic $(0.9 \%, 4.3 \%, 3.4 \%$, respectively) of existential therapy (Correia et al., 2016). These were observed at analysed sessions, but again without a marked expression.

\section{Adherence to Existential-Specific Procedures}

Phenomenology and existential assumptions are actually applied in real existential therapy sessions, and this can be observed once specific instruments are designed to capture it. But the use of these existential-specific practices was not as frequent in the observed sessions as expected, attending to the relevance it is given in the existential therapy literature and the frequency it appeared in Correia et al.'s (2016) responses (even if frequency of self-reported practices and adherence in real practice may not be directly comparable measures).

Methods associated with specific existential branches were not identified a single time in observed sessions. Participant therapists identify themselves with the existential-phenomenological branch, thus this absence does not necessarily express that these existential-specific methods are not used by existential practitioners, but do corroborate (in the real practice context) Correia et al.'s (in press) findings which relate these practices almost exclusively with the logotherapy and/or existential analysis branch. 


\section{Challenging Findings to an Existential Theory of Practice}

Relational practices are frequently addressed by the existential literature (and research) as pivotal to any existential therapeutic encounter but, contrary to Correia et al. (2016) it was unexpected that these interventions represented almost half of all therapists' interventions. The frequent use of interpretations and reformulations was also unexpected considering the relevant literature, previous research and Correia et al.'s (2016) results. And finally, given both the existential literature and self-reported worldwide results from existential therapists (Correia et al., 2016), a more frequent use was expected in the present study of both phenomenological practices (in particular, the application of the phenomenological method) and existential assumptions.

The framework of existential practices resulting from the Correia et al. (2016) results helped to develop an applicable observational grid. But observation of real sessions revealed that at least the Portuguese existential therapists observed do not use as much existential-specific procedures as the literature and Correia et al. (2016) would eventually suggest. Relational practices, interpretations and reformulations (paraphrasing), are all bona fide therapeutic practices (Cooper, 2008), but far from being existential-specific, these methods are frequently used by therapists from all different theoretical alignments (Cooper, 2008). These findings raise two related fundamental questions: a) Is the relevance of existential-specific practices more of a theoretical concern than a useful and frequently applicable instrument for real practice contexts and problems? b) Are existential therapists simply using well tested and effective procedures most of the time, just like therapists from other theoretical sources? 
However, present findings should be read carefully, as they stem from a small and circumscribed sample and reliability issues and several methodological limitations were found in this exploratory study, as will be explained.

\section{Therapist, Client, and Dyad Uniqueness}

The degree to which different practices were used varied significantly by therapist, and two of them were using certain practices over others depending on their clients. These findings corroborate, in part, existential therapists' proposition of the uniqueness of every therapeutic encounter (Bugental, 1990; Deurzen, 2012; Spinelli, 2007).

\section{Limitations, Further Research and Implications for Practice}

Clients were primarily women, while raters were both men, and a single female therapist participated. It is impossible to predict how these gender ratios may have influenced the therapists' practices and the raters' observations. Likewise, the relative homogeneity of the raters' race, gender, cultural and educational background may have influenced both the development of the observational grid and the rating of sessions in ways that could possibly be prevented via a greater diversity among the raters. The fact that neither rater was an expert in existential psychotherapy may have prevented the overrating of specific existential practices, or the opposite may have happened due to their lack of experience in handling or recognizing these practices. 
Several attempts to improve the observational grid led to a more practical and applicable instrument. Still, as the analysts' feedback and the final inter-rater agreement for the EPOG shows, it is still an instrument in need of further refinement built on the clarification of the operational definitions and the development of mutually exclusive categories.

The major doubts and disagreements found on rating both phenomenology and existential assumptions clearly underlines the need for further definition and delineation of the observable expressions of these practices to make them easily and objectively observable for any rater. It is possible that phenomenological and, particularly, existential assumptions may be enacted at a not immediately observable level. For instance, a therapist may perform a few interventions guided by the thought of exploring or helping the client to acknowledge his finitude but, at the manifested level of a speaking turn, what is heard are interventions that would be rated in other ways (e.g., "Tell me a little more about it." [TA2-13'11'] or "What are you seeking?" [TD13'38']). Whole session analysis was an attempt to overcome the problem of the speaking turn being too small a unit of analysis to identify some practices. But several therapists' interventions are attitudinal or/and a result of an ongoing process that may not be directly and objectively observable, even using larger units of analysis.

To overcome these difficulties and refine the EPOG, different research paths are suggested: a) Similar to other existing studies (e.g., Michie et al., 2013), to develop an extensive consensually agreed definition and operationalization of the existential practices, from an international pool of experts built on formal consensus development methods (e.g., Delphi technique); b) To deepen the clarification of existential practices, based on a literature review of existential therapy's most influential authors; c) Develop a study where the rater listens to the session together with the therapist, in order to 
clarify the practice intended at each speaking turn (suggested questions: What practice did you use right now? And how do you think that is expressed in what we hear/see?).

These research proposals will help to clarify and delineate the observable expression of several practices, in particular phenomenological practices and those informed by existential assumptions.

The other practices item reported mainly reformulations. An independent item for reformulations may be necessary if a similar pattern appears in future studies.

To overcome the redundancy and low frequency count problems found with the first two iterations of the observational grid, the panel's solution was to subsume specific practices under higher order categories. This solution was not totally effective and led to a grid focused on capturing broader categories of intervention that does not allow for detailed data concerning very specific interventions. Future developments should also attend to the advantages of developing more discriminative observational items.

Further studies need to include larger samples and therapists from different existential branches and different countries, in order to understand if the present results stem from idiosyncrasies within the Portuguese school of existential therapy. A larger study is also encouraged to corroborate and deepen the understanding of the differences among therapists as well as within the same therapist depending on his or her clients.

\section{Conclusion}


The present research was a first, exploratory attempt to develop an observational instrument based on an international empirical survey of existential therapy's most characteristic practices.

Several obstacles were encountered while developing the observational grid and the low final inter-rater agreement reinforces the need for further definition and operationalization of the self-reported existential practices.

Despite these limitations, results from the observational study may indicate that there is a difference between what both literature and practitioners indicate existential practice should be and what is really practised: That existential therapy's theory of practice and its existential-specific practices work more as a conceptual framework for the intervention rationale, rather than as a directly and frequently applicable instrument. The present findings indicate that existential therapy seems to rely mostly on relational attitudes and practices and that existential therapists use more interpretations (even if based exclusively on the contents brought to the session by the client) and reformulations than they acknowledge. Phenomenology and existential assumptions were observable in applied practices, although some difficulties were found in rating them and their prevalence was not as marked as both literature and the self-reported worldwide study led us to anticipate.

Data from this exploratory study must be interpreted carefully as it derives from practitioners of a single school of existential-phenomenological therapy and from a first exploratory attempt to apply an observational grid based on specific existential practices. Future studies are encouraged to improve and overcome present grid limitations, particularly to refine the observation of existential assumptions and phenomenological practices. 


\section{References}

Alegria, S., Carvalho, I., Sousa, D., Correia, E. A., Fonseca, J., Pires, B. S., \& Fernandes, S. (2016). Process and outcome research in existential psychotherapy. Existential Analysis, 27(1), 78-92.

Barkham, M., Mellor-Clark, J., Connell, J., \& Cahill, J. (2006). A core approach to practice-based evidence: A brief history of the origins and applications of the CORE-OM and CORE System. Counselling \& Psychotherapy Research, 6(1), 3-15. doi: 10.1080/14733140600581218.

Barnett, L., \& Madison, G. (Eds.). (2012). Existential therapy: Legacy, vibrancy and dialogue. London: Routledge.

Bugental, J. F. (1990). Intimate journeys: Stories from life-changing therapy. San Francisco: Jossey-Bass Publishers.

Carter, J. D., Crowe, M., Carlyle, D., Frampton, C. M., Jordan, J., McIntosh, V. V. W., . . Joyce, P. R. (2012). Patient change processes in psychotherapy: Development of a new scale. Psychotherapy Research, 22(1), 115-126. doi: 10.1080/10503307.2011.631195.

Cooper, M. (2004). Towards a relationally-orientated approach to therapy: Empirical support and analysis. British Journal of Guidance and Counselling, 32(4), 451460.

Cooper, M. (2008). Essential Research Findings in Counselling and Psychotherapy: The Facts are Friendly. London: Sage.

Cooper, M. (2012). The existential counselling primer: A concise, accessible and comprehensive introduction. Ross-on-Wye: PCCS. 
Cooper, M. (2015). Existential psychotherapy and counselling: Contributions to a pluralistic practice. London: Sage.

Correia, E. A. (2005). Alterity and psychotherapy. Existential Analysis: Journal of the Society for Existential Analysis, 16(1), 61-72.

Correia, E. A., Cooper, M., \& Berdondini, L. (2014). The worldwide distribution and characteristics of existential counsellors and psychotherapists. Existential Analysis, 25(2), 321-337.

Correia, E. A., Cooper, M., \& Berdondini, L. (2015). Existential psychotherapy: An international survey of the key authors and texts influencing practice. Journal of Contemporary Psychotherapy, 45(1), 3-10. doi: 10.1007/s10879-014-9275-y.

Correia, E. A., Cooper, M., Berdondini, L., \& Correia, K. (2015). Existential psychotherapies: Similarities and differences among the main branches. Manuscript submitted for publication.

Correia, E. A., Cooper, M., Berdondini, L., \& Correia, K. (2016). Characteristic practices of existential psychotherapy: A worldwide survey of practitioners' perspectives. Manuscript submitted for publication.

Correia, E. A., Cooper, M., Berdondini, L., \& Correia, K. (in press). Existential psychotherapies: Similarities and differences among the main branches. Journal of Humanistic Psychology. doi: 10.1177/0022167816653223.

Correia, E. A., Correia, K., Cooper, M., \& Berdondini, L. (2014a). Práticas da psicoterapia existencial em Portugal e no Brasil: Aguns dados comparativos. In A. M. L. Feijoo \& M. B. Lessa (Eds.), Fenomenologia e práticas clínicas (pp. 47-72). Rio de Janeiro: Edições IFEN. 
Correia, E. A., Correia, K., Cooper, M., \& Berdondini, L. (2014b). Psicoterapia existencial latinoamericana en la actualidad. Revista Latinoamericana de Psicología Existencial, 9, 26-37.

Deurzen, E. v. (2012). Existential counselling \& psychotherapy in practice (3 ed.). London: Sage Publications.

Deurzen, E. v., \& Adams, M. (2011). Skills in existential counselling \& psychotherapy. London: Sage Publications.

du Plock, S., \& Deurzen, E. v. (2015). The historical development and future of existential therapy. International Journal of Psychotherapy, 19(1), 5-14.

Elliott, R. (1993). Comprehensive process analysis: Mapping the change process in psychotherapy. Unpublished manuscript. Department of Psychology. University of Toledo. Toledo.

Froján-Parga, M. X., Calero-Elvira, A., \& Montaño-Fidalgo, M. (2011). Study of the Socratic method during cognitive restructuring. Clinical Psychology \& Psychotherapy, 18(2), 110-123. doi: 10.1002/cpp.676.

Gonçalves, M. M., Ribeiro, A. P., Mendes, I., Matos, M., \& Santos, A. (2011). Tracking novelties in psychotherapy process research: The innovative moments coding system. Psychotherapy Research, 21(5), 497-509. doi:

10.1080/10503307.2011.560207.

Keshen, A. (2006). A new look at existential psychotherapy. American Journal of Psychotherapy, 60(3), 285-298.

Landis, J. R., \& Koch, G. G. (1977). The measurement of observer agreement for categorical data. Biometrics, 33(1), 159-174.

Längle, A. (2003). The method of "personal existential analysis". European Psychotherapy, 4(1), 59-75. 
Längle, A. (2013). Lehrbuch zur existenzanalyse: Grundlagen. Wien: Facultas.wuv.

Lantz, J. (2004). Research and Evaluation Issues in Existential Psychotherapy. Journal of Contemporary Psychotherapy, 34(4), 331-340. doi: 10.1007/s10879-0042527-5.

Martínez, Y. A. (2012). Psicoterapia existencial. Teoría y práctica relacional para un mundo post-Cartesiano. México: Diana Reyes Trigos.

McLeod, B. D., Smith, M. M., Southam-Gerow, M. A., Weisz, J. R., \& Kendall, P. C. (2015). Measuring treatment differentiation for implementation research: The Therapy Process Observational Coding System for Child Psychotherapy Revised Strategies Scale. Psychological Assessment, 27(1), 314-325. doi: $10.1037 /$ pas0000037.

Michie, S., Richardson, M., Johnston, M., Abraham, C., Francis, J., Hardeman, W., . . Wood, C. E. (2013). The behavior change technique taxonomy (v1) of 93 hierarchically clustered techniques: Building an international consensus for the reporting of behavior change interventions. Annals of Behavioral Medicine, 46(1), 81-95. doi: 10.1007/s12160-013-9486-6.

Norcross, J. C. (1987). A rational and empirical analysis of existential psychotherapy. Journal of Humanistic Psychology, 27(1), 41-68. doi: $10.1177 / 0022167887271005$.

Perepletchikova, F., Treat, T. A., \& Kazdin, A. E. (2007). Treatment integrity in psychotherapy research: Analysis of the studies and examination of the associated factors. Journal of Consulting and Clinical Psychology, 75(6), 829841. doi: 10.1037/0022-006x.75.6.829.

Rayner, M., \& Vitali, D. (2014). CORE Blimey! Existential therapy score GOALS! Existential Analysis, 25(2), 296-312. 
Rubel, J., Lutz, W., \& Schulte, D. (2015). Patterns of change in different phases of outpatient psychotherapy: A stage-sequential pattern analysis of change in session reports. Clinical Psychology \& Psychotherapy, 22(1), 1-14. doi: 10.1002/cpp.1868.

Schneider, K. J. (2008). Part 2: Guideposts to an existential-integrative (EI) approach. In K. J. Schneider (Ed.), Existential-integrative psychotherapy: Guideposts to the core of practice (pp. 31-96). New York: Routledge.

Smith-Hansen, L., Levy, R. A., Seybert, C., Erhardt, I., \& Ablon, J. S. (2012). The contributions of the Psychotherapy Process Q-set to psychotherapy research. In R. A. Levy, J. S. Ablon \& H. Kächele (Eds.), Psychodynamic psychotherapy research: Evidence-based practice and practice-based evidence. (pp. 381-400). Totowa, NJ, US: Humana Press.

Sousa, D. (2015). Existential psychotherapy the genetic-phenomenological approach: Beyond a dichotomy between relating and skills. Journal of Contemporary Psychotherapy, 45(1), 69-77. doi: 10.1007/s10879-014-9283-y.

Spinelli, E. (2007). Practising existential psychotherapy: The relational world. London: Sage Publications.

Spinelli, E. (2008). The value of relatedness in existential psychotherapy and phenomenological enquiry. Gestalt Journal of Australia \& New Zealand, 4(2), $56-69$.

Teixeira, J. A. C. (1996). A relação terapêutica em psicoterapias existenciais. In R. G. Lopes, V. Mota \& C. Santos (Eds.), A escolha de si-próprio (pp. 51-58). Porto: Hospital de Conde de Ferreira.

van Kaam, A. (1966). The art of existential counseling. Wilkes-Barre: Dimension Books. 
Vos, J., Cooper, M., Correia, E., \& Craig, M. (2015a). Existential Therapies: A review of scientific studies and their underlying philosophies. International Journal of Psychotherapy, 19(1), 47-57.

Vos, J., Cooper, M., Correia, E., \& Craig, M. (2015b). Existential therapies: A review of their scientific foundations and efficacy. Existential Analysis, 26(1), 49-69.

Yalom, I. D. (2001). The gift of therapy: Reflections on being a therapist. London:

Piatkus. 
Table 1

Sample of a Coded Segment

Dyad Interv. Transcription Rating

Client: (breathes deeply) ... I'm tired!

1'18' Therapist: You are tired. (with a very low tone Relational of voice) practices

\begin{tabular}{lll} 
& Of voice & practices \\
\hline 1'38', & $\begin{array}{l}\text { Client: ... (Silence and a deep breath) } \\
\text { Therapist: It seems that there was a deep } \\
\text { breath after telling me that. }\end{array}$ & $\begin{array}{l}\text { Experiential and } \\
\text { body practices }\end{array}$ \\
\end{tabular}

$$
\text { Client: (Silence and another deep breath) ... I }
$$

1'57', think I tire myself...

Other practices

Therapist: You are tired, and you feel that you (reformulation) are the one who leaves you feeling like that.

Client: Since I returned to smoking I've been trying to stop, and... (Sighs) ... it's hard ... Last

TC 1 week I did a hypnotherapy session, and... and stopped. On Friday I stopped smoking, but I

2'55', returned ... I return to smoking yesterday ... and... I smoked four or five cigarettes. After that, I crumbled the remaining cigarettes and Relational practices threw them in the garbage. But this morning, very early, I bought another packet.

Therapist: ... You resumed yesterday ...

Anything important yesterday?

Client: ... (Deep breath) Well, yesterday no.

But, when I said I tire myself... I do things... I get into things that trigger... old mechanisms of

3'56' fear, insecurity, fragility, vulnerability and yet... and yet these are things that I feel I must (reformulation) do...

Therapist: Turns out to be stronger... and you feel you must do it anyway.

\begin{tabular}{lll}
\hline 4'04'” & Client: Yes I feel ... Yes, yes, yes... & Relational \\
Therapist: So, what happened? & practices
\end{tabular}

Note. Ratings were given on the Portuguese audio-recorded sessions. Present transcripts were a direct and personal translation made by the first author. This informal translation may not accurately represent the original interaction on which ratings were based. 
Table 2

Frequencies and percentages of practices at the speaking turn level of analysis

\begin{tabular}{lcc}
\hline \multicolumn{1}{c}{ Practices } & Frequency & Percentage \\
$\%$
\end{tabular}


Table 3

Percentages of practices at the whole session level of analysis

\begin{tabular}{|c|c|c|c|c|c|}
\hline Practices & $\begin{array}{c}\text { Not } \\
\text { present }\end{array}$ & $\begin{array}{c}\text { Rarely } \\
\%\end{array}$ & $\begin{array}{c}\text { Occasionally } \\
\%\end{array}$ & $\begin{array}{c}\text { Frequent } \\
\%\end{array}$ & $\begin{array}{c}\text { Very } \\
\text { Frequent }\end{array}$ \\
\hline Relational practices & 0 & 3.1 & 3.1 & 12.5 & 81.3 \\
\hline Hermeneutic interventions & 0 & 6.3 & 12.5 & 34.4 & 46.9 \\
\hline Other practices & 12.5 & 15.6 & 34.4 & 18.8 & 18.8 \\
\hline Phenomenological practices & 18.8 & 43.8 & 31.3 & 6.3 & 0 \\
\hline $\begin{array}{l}\text { Directive/confrontational } \\
\text { interventions }\end{array}$ & 37.5 & 34.4 & 28.1 & 0 & 0 \\
\hline $\begin{array}{l}\text { Addressing what is happening in the } \\
\text { therapeutic relation }\end{array}$ & 78.1 & 15.6 & 3.1 & 3.1 & 0 \\
\hline $\begin{array}{l}\text { Practices informed by existential } \\
\text { assumptions }\end{array}$ & 84.4 & 12.5 & 3.1 & 0 & 0 \\
\hline Experiential and body practices & 90.6 & 9.4 & 0 & 0 & 0 \\
\hline $\begin{array}{l}\text { Methods associated with specific } \\
\text { existential branches }\end{array}$ & 100 & 0 & 0 & 0 & 0 \\
\hline
\end{tabular}


Table 4

Percentages of practices by therapist

\begin{tabular}{lcccc}
\hline \multicolumn{1}{c}{ Practices } & TA & TB & TC & TD \\
& $\%$ & $\%$ & $\%$ & $\%$ \\
\hline Relational practices & 48.4 & 52.5 & 36.5 & 53.2 \\
Hermeneutic interventions & 31 & 29.1 & 32.1 & 25.3 \\
Other practices & 10.7 & 6.5 & 18.6 & 13 \\
Phenomenological practices & 9.1 & 3.2 & 3.6 & 6 \\
Directive/confrontational & 0.8 & 7.6 & 3.6 & 1.6 \\
interventions & 0 & 1.1 & 5.6 & 0.9 \\
ATR; PIEA; EBP & &
\end{tabular}

Note. $\mathrm{ATR}=$ Addressing what is happening in the therapeutic relation; PIEA = Practices informed by existential assumptions; $\mathrm{EBP}=$ Experiential and body practices 
Table 5

Percentages of practices by dyad

\begin{tabular}{|c|c|c|c|c|c|c|c|c|}
\hline \multirow{2}{*}{ Practices } & \multicolumn{2}{|c|}{ TA $\%$} & \multicolumn{2}{|c|}{ TB $\%$} & \multicolumn{2}{|c|}{ TC \% } & \multicolumn{2}{|c|}{ TD \% } \\
\hline & 1 & 2 & 1 & 2 & 1 & 2 & 1 & 2 \\
\hline Relational practices & 42.1 & 55.5 & 56.8 & 49.4 & 36.4 & 36.6 & 53.5 & 52.8 \\
\hline $\begin{array}{l}\text { Hermeneutic } \\
\text { interventions }\end{array}$ & 37.6 & 23.5 & 25.4 & 31.9 & 34.7 & 24.8 & 27.4 & 22.3 \\
\hline Other practices & 11.3 & 10.1 & 5.9 & 6.9 & 16.2 & 25.7 & 12.2 & 14.1 \\
\hline $\begin{array}{l}\text { Phenomenological } \\
\text { practices }\end{array}$ & 8.3 & 10.1 & 0.8 & 5 & 3.1 & 5 & 3.5 & 9.3 \\
\hline $\begin{array}{l}\text { Directive/confrontation } \\
\text { al interventions }\end{array}$ & 0.8 & 0.8 & 9.3 & 6.3 & 2.7 & 5.9 & 1.9 & 1.1 \\
\hline ATR; PIEA; EBP & 0 & 0 & 1.7 & 0.6 & 6.9 & 2 & 1.4 & 0.4 \\
\hline
\end{tabular}

Note. $\mathrm{ATR}=$ Addressing what is happening in the therapeutic relation; PIEA $=$ Practices informed by existential assumptions; $\mathrm{EBP}=$ Experiential and body practices 